\title{
Effects of patient age on patency of chronic hemodialysis vascular access
}

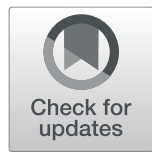

\author{
Seonjeong Jeong ${ }^{1}$, Hyunwook Kwon¹, Jai Won Chang², Min-Ju Kim³, Khaliun Ganbold', Youngjin Han', \\ Tae-Won Kwon ${ }^{1}$ and Yong-Pil Cho ${ }^{1 *}$ (D)
}

\begin{abstract}
Background: In this single-center, retrospective observational study, we assessed the long-term patency of vascular access (VA) after first VA placement to uncover independent risk factors associated with VA patency in Asian hemodialysis (HD) patients stratified by age. We also investigated factors associated with VA patency among older HD patients according to the type of VA in the overall study population.

Methods: The study period was from January 2011 to December 2013. A total of 651 chronic HD patients with confirmed first upper-extremity VA placement were enrolled, and their records were analyzed retrospectively. A total of 445 patients (68.4\%) made up the nonelderly group (<65 years), and 206 patients (31.6\%) were in the elderly group ( $\geq 65$ years). Study outcomes were defined as primary or secondary VA patency.

Results: Autologous arteriovenous fistula (AVF) was more common in the nonelderly group $(P<0.01)$. KaplanMeier curve survival analysis indicated that primary patency was longer in the nonelderly group $(P<0.01)$; secondary patency, however, was similar between groups $(P=0.37)$. The multivariate analysis of factors associated with primary VA patency revealed that increased age (hazard ratio [HR], 1.02; 95\% confidence interval [CI], 1.01-1.03; $P<0.01)$ was associated with shorter primary patency, and AVF (HR, 0.38; 95\% Cl, $0.28-0.51 ; P<0.01)$ was associated with longer primary patency. AVF (HR, 0.57; $95 \% \mathrm{Cl}, 0.37-0.87 ; P=0.010)$ and diabetes mellitus (HR, 1.56; $95 \% \mathrm{Cl}, 1.07-2.29 ; P=0.02)$ were independently associated with longer and shorter secondary patency periods, respectively; however, increased age was not a risk factor for decreased secondary patency.
\end{abstract}

Conclusions: Increased age was associated with shorter primary patency but not secondary patency, whereas AVF placement was associated with longer primary and secondary patency. Considering the similar rates of secondary patency between groups and the superior patency of AVF compared to arteriovenous graft, a fistula-first strategy should be applied to appropriate older patients.

Keywords: Age, arteriovenous fistula, arteriovenous graft, Chronic kidney disease, renal dialysis

\section{Background}

The number of patients over 65 years of age diagnosed with chronic kidney disease (CKD) and requiring renal replacement therapy has been steadily increasing [1]. Although fistula-first is the recommended strategy for all hemodialysis (HD) patients [2-4], and age has not been found to be a significant contributing factor to the patency of functioning autologous arteriovenous fistulas (AVFs) across several studies [5-8], controversy remains

\footnotetext{
* Correspondence: ypcho@amc.seoul.kr

${ }^{1}$ Division of Vascular Surgery, Department of Surgery, University of Ulsan College of Medicine and Asan Medical Center, 88, Olympic-ro 43-gil, Songpa-gu, Seoul 05505, Republic of Korea

Full list of author information is available at the end of the article
}

regarding whether fistula-first is appropriate for elderly HD patients [9-13]. AVF placement in elderly patients is more challenging because of their relatively higher incidence of comorbidities and operative risks, longer AVF maturation times, limited life expectancies, and recent data indicating a lack of a survival benefit compared with arteriovenous graft (AVG) or central venous catheter (CVC) use [8-10, 14-16]. Factors influencing management decisions in older HD patients, including the optimal type of vascular access (VA), differ from considerations for younger patients.

This study compared long-term VA patency in an Asian HD patient population with confirmed first VA

(c) The Author(s). 2019 Open Access This article is distributed under the terms of the Creative Commons Attribution 4.0 International License (http://creativecommons.org/licenses/by/4.0/), which permits unrestricted use, distribution, and 
placement stratified by age ( $<65$ years vs. $\geq 65$ years) and evaluated potential independent risk factors associated with VA patency in these patients. We also investigated factors associated with VA patency among subgroups of patients 65 years and older and according to VA type in the overall study population.

\section{Methods}

\section{Study design and patient population}

This single-center, observational study was conducted retrospectively using data extracted from the medical records of chronic HD patients. The study protocol was approved by the Institutional Review Board (2018-1318) at our hospital, which waived the need for informed consent because of the retrospective nature of the study.

A total of 876 patients aged 20 years and older with confirmed first upper-extremity VA placement for HD at our hospital between January 1, 2011, and December 31, 2013 were screened for this study. Of these, 694 with AVFs (79.2\%) and 182 with AVGs (20.8\%) were collected. We excluded patients lost to follow up $(n=89$, $10.2 \%)$ and those with a malignancy $(n=136,15.5 \%)$. A final total of $651 \mathrm{HD}$ patients (74.3\%) was stratified by patient age with the nonelderly group including patients less than 65 years and the elderly group including patients at least 65 years at the time of VA placement. Data were analyzed retrospectively. We then examined the association between clinical variables and outcomes in the elderly group using Cox proportional hazard regression models. We also evaluated the association between clinical variables and outcomes according to AVF versus AVG VA. The elderly group was then subdivided for subgroup analyses into those from 65 to 74 years of age and those at least 75 years of age. In our study population, a nephrologist was involved with each patient for all medication adjustments, planning of VA type and HD initiation, and VA surveillance [17].

\section{Index procedures and definitions}

The preferred option for VA placement is AVF, followed by AVG, at the most distal site of the nondominant arm that satisfies necessary criteria for vessel suitability, as evaluated by physical examination alone or with supplemental duplex ultrasound. All VA placement procedures were performed under local anesthesia by specially trained vascular surgeons, as described in previous publications [17-20]. VA types were categorized as AVF (forearm or upper arm) or AVG (straight or U-shaped forearm graft or straight upper arm graft). Postoperative surveillance was conducted in accordance with the clinical practice guidelines of the Society for Vascular Surgery regarding surgical placement and maintenance of arteriovenous HD access [17, 21].
VA performance was defined as described in previous publications [17-21]. A functioning VA allowed for at least six adequate HD sessions with successful twoneedle cannulation without VA-related complications. Primary VA patency was defined from the time of VA placement until the first intervention to preserve or restore blood flow, first VA failure, or study end, whichever occurred first. Secondary VA patency was defined from the time of VA placement until VA abandonment for any cause, regardless of the number of subsequent interventions [17, 18, 22, 23]. Early mortality was defined as all-cause mortality that occurred within 3 months of VA placement but prior to its use, with HD maintained via CVC. AVF maturation failure was defined as an AVF inadequate for successful needle cannulation after placement $[23,24]$. Early thrombosis was defined as the absence of thrill or flow on duplex ultrasound or fistulogram within 30 days of HD initiation via a functioning VA [25]. Body mass index (BMI) was defined as weight in $\mathrm{kg}$ divided by height in $\mathrm{m}^{2}$ at the time of VA placement. Peripheral arterial occlusive disease (PAOD) was defined as a previous history of any therapeutic interventions for PAOD or an ankle-brachial index less than or equal to 0.9 as measured by Doppler ultrasound [26].

\section{Study outcomes and follow-up}

Study outcomes of interest were primary and secondary VA patency. Formal follow-up visits by clinical examination alone or with supplemental duplex ultrasound were conducted at the Vascular Surgery out-patient clinic to assess VA performance at 1 and 6 weeks after VA placement. Once stability was established, clinical surveillance at our facility was terminated. Follow-up visits with laboratory assessments at the Nephrology out-patient clinic were planned at approximately 6month intervals, and the latest follow-up data were obtained from medical records or follow-up physicians. For patients receiving follow-ups at other centers, telephone interviews with the patients or their family members were conducted to obtain information about each patient's general health status, the function of the original $\mathrm{VA}$, and all diagnostic and therapeutic interventions during the interim. Risk factors of interest, clinical characteristics, and long-term clinical outcomes for all patients were recorded in an Excel database (Microsoft Corp., Redmond, WA, USA) and analyzed retrospectively.

\section{Statistical analysis}

Data were recorded in an Excel database, and patients in the nonelderly and elderly groups were compared. Categorical variables are reported as frequencies or percentages, and continuous variables as means or standard 
deviations. Differences between the two groups were assessed using the chi-squared test for categorical variables and Student's $t$-test for continuous variables. Longterm event-free rates were analyzed by Kaplan-Meier curve. Long-term event-free rates were compared between patients less than 65 and at least 65 years, with estimations calculated using the log-rank test. Univariate and multivariate analyses of the associations between clinical variables and study outcomes (primary and secondary VA patency) were performed with Cox proportional hazards modeling. This analysis utilized the event of interest and the time interval from VA placement to the date of the event or last follow-up as the outcome. We adapted univariate Cox proportional hazard regression models to calculate hazard ratios (HRs) with 95\% confidence intervals (CIs). Using the Cox regression model, we evaluated the associations between clinical variables and outcomes. Variables with a $P$-value of less than 0.1 on univariate analysis were included in the multivariate analysis. A $P$-value of less than 0.05 was considered statistically significant. Statistical analyses were performed with SPSS version 21.0 (IBM Corp., Armonk, NY, USA).

\section{Results}

The study cohort consisted of 651 chronic HD patients with first VA placements from our hospital, stratified by age into nonelderly $(n=445,68.4 \%)$ and elderly $(n=206$, $31.6 \%)$ groups. No mortality or morbidity was associated with VA placement. The baseline and clinical characteristics of the study population are presented in Table 1 . AVF placement was performed more often in the nonelderly group $(P<0.01)$ than the elderly group. The elderly group had a higher prevalence of atherosclerotic risk factors and comorbidities than the nonelderly group. The proportion of patients taking antiplatelet medications $(P<0.01)$ and of those with early mortality $(P<0.01)$ were significantly higher in the elderly group, whereas there were no significant differences in AVF maturation failure $(P=0.80)$ or early VA thrombosis $(P=0.16)$ between the two groups.

A Kaplan-Meier survival analysis revealed that primary VA patency was significantly longer in the nonelderly group $(P<0.01)$, whereas secondary patency was similar between the two groups $(P=0.37)$ (Fig. 1). Elderly patients had a reduced primary patency rate at all time points compared with nonelderly patients. The mean durations of primary and secondary VA patency for the nonelderly group were 62.9 months $(95 \% \mathrm{CI}$, 59.6-66.2 months) and 75.1 months (95\% CI, 72.4-77.8 months), respectively. For the elderly group, these values were 47.6 months (95\% CI, 41.6-53.5 months) and 74.9 months (95\% CI, 69.9-79.9 months), respectively.
Table 1 Baseline demographics and clinical characteristics of the study population at the time of VA placement according to patient age

\begin{tabular}{|c|c|c|c|}
\hline & $\begin{array}{l}<65 \text { years } \\
n=445\end{array}$ & $\begin{array}{l}\geq 65 \text { years } \\
n=206\end{array}$ & $P$-value \\
\hline Age (years) & $50.0 \pm 10.2$ & $72.7 \pm 5.5$ & $<0.01$ \\
\hline Female sex & $169(38.0)$ & $92(44.7)$ & 0.11 \\
\hline BMI $\left(\mathrm{kg} / \mathrm{m}^{2}\right)$ & $23.3 \pm 3.6$ & $23.1 \pm 3.7$ & 0.46 \\
\hline \multicolumn{4}{|l|}{ Type of VA } \\
\hline AVF & $398(89.4)$ & $123(59.7)$ & $<0.01$ \\
\hline Forearm & $206(51.8)$ & $58(47.2)$ & 0.37 \\
\hline Upper arm & $192(48.2)$ & $65(52.8)$ & \\
\hline AVG & $47(10.6)$ & $83(40.3)$ & \\
\hline Forearm & $24(51.1)$ & $25(30.1)$ & 0.02 \\
\hline Upper arm & $23(48.9)$ & $58(69.9)$ & \\
\hline On hemodialysis & $232(52.1)$ & $127(61.7)$ & 0.02 \\
\hline \multicolumn{4}{|l|}{ Underlying diseases } \\
\hline Hypertension & $373(83.8)$ & $181(87.9)$ & 0.18 \\
\hline $\mathrm{DM}$ & $200(44.9)$ & $124(60.2)$ & $<0.01$ \\
\hline Smoker & 105 (23.6) & $44(21.4)$ & 0.53 \\
\hline CVD & $55(12.4)$ & $71(34.5)$ & $<0.01$ \\
\hline CVA & $31(7.0)$ & $43(20.9)$ & $<0.01$ \\
\hline PAOD & $19(4.3)$ & $17(8.3)$ & 0.04 \\
\hline \multicolumn{4}{|l|}{ Medications } \\
\hline Anti-platelets & $184(41.3)$ & $122(59.2)$ & $<0.01$ \\
\hline Anti-coagulants & $28(6.3)$ & $11(5.3)$ & 0.63 \\
\hline Early mortality ${ }^{\mathrm{a}}$ & $12(2.7)$ & $16(7.8)$ & $<0.01$ \\
\hline Maturation failure ${ }^{b}$ & $26(5.8)$ & $11(5.3)$ & 0.80 \\
\hline Early thrombosis ${ }^{c}$ & $12(2.7)$ & $10(4.9)$ & 0.16 \\
\hline
\end{tabular}

Continuous data are expressed as mean \pm standard deviation, and categorical data as number (\%)

AVF Autologous arteriovenous fistula, AVG Arteriovenous graft, BMI Body mass index, CVA History of cerebrovascular accident, CVD Cardiovascular disease,

$D M$ Diabetes mellitus, PAOD Peripheral arterial occlusive disease, VA Vascular access

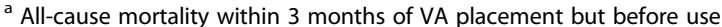

${ }^{\mathrm{b}}$ AVF maturation failure

c Absence of thrill and/or flow within 30 days of hemodialysis initiation via a functioning $V A$

Clinical variables associated with study outcomes were analyzed using univariate and multivariate Cox proportional hazards regression. In the adjusted models, increased age (HR, 1.02; 95\% CI, 1.01-1.03; $P<0.01$ ) was significantly associated with shorter primary patency, whereas type of VA (AVF) (HR, 0.38; 95\% CI, 0.28-0.51; $P<0.01)$ was a positive predictor for longer primary patency (Table 2). An analysis of the associations between 

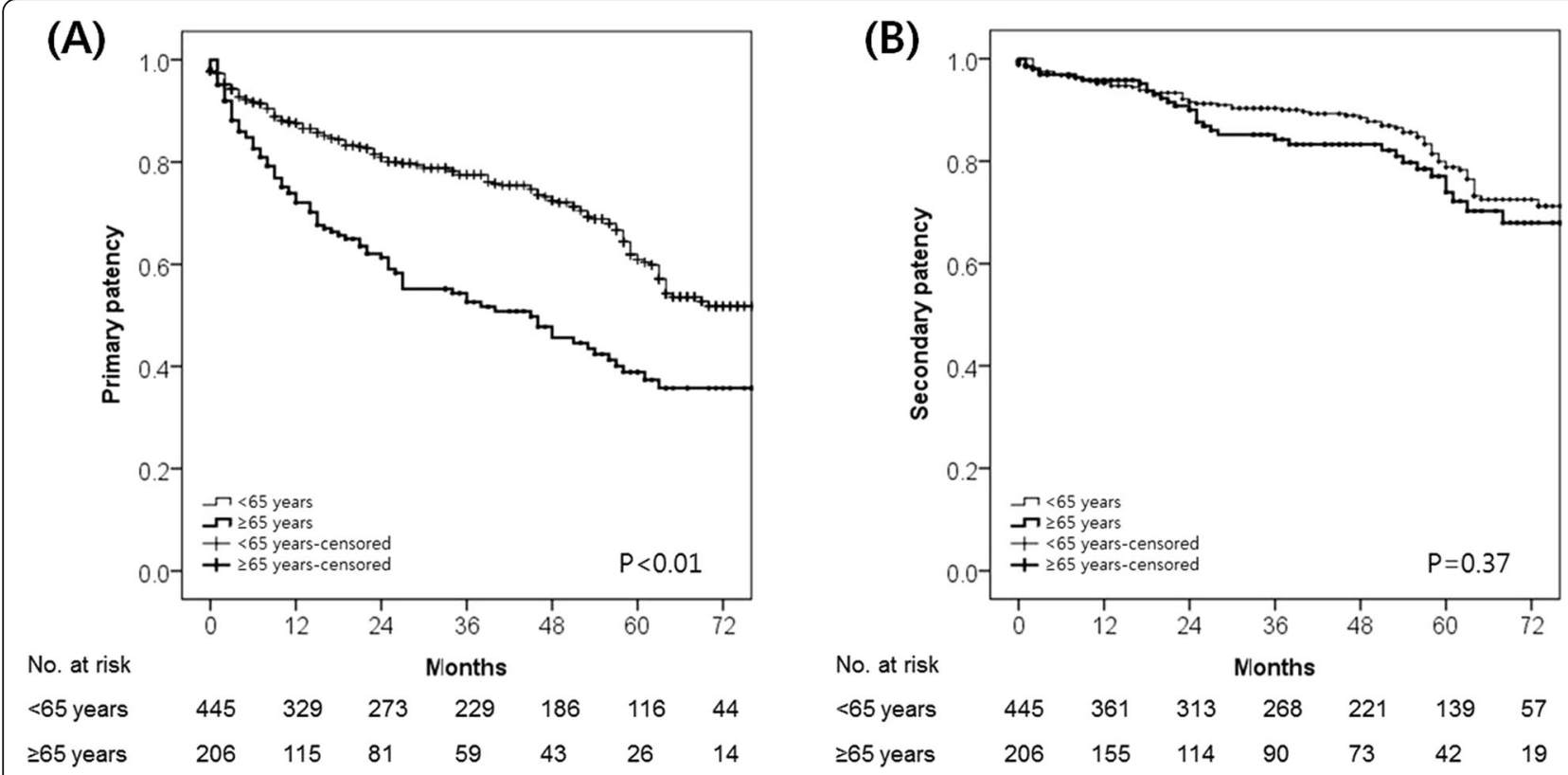

Fig. 1 Kaplan-Meier survival analysis. Kaplan-Meier estimates of (a) primary and (b) secondary patency rates in the study population stratified by age ( $<65$ years vs. $\geq 65$ years)

clinical variables and secondary VA patency was conducted, and AVF (HR, 0.57; 95\% CI, 0.37-0.87; $P=$ $0.010)$ and diabetes mellitus (DM) (HR, 1.56; 95\% CI, $1.07-2.29 ; P=0.02$ ) were independently associated with longer or shorter secondary patency, respectively. Of note, increased age was not associated with secondary patency duration (Table 3). In our analysis, female sex was not a significant risk factor in primary or secondary VA patency, probably due to the higher proportion of AVG placements in females than males; there were 190

Table 2 Factors associated with primary VA patency

\begin{tabular}{|c|c|c|c|c|}
\hline & \multicolumn{2}{|l|}{ Univariate } & \multicolumn{2}{|l|}{ Multivariate } \\
\hline & HR $(95 \%$ Cl) & $P$-value & $\mathrm{HR}(95 \% \mathrm{Cl})$ & $P$-value \\
\hline Increased age & $1.03(1.02-1.04)$ & $<0.01$ & $1.02(1.01-1.03)$ & $<0.01$ \\
\hline Female sex & $1.04(0.80-1.35)$ & 0.76 & NA & NA \\
\hline BMI & $0.97(0.94-1.01)$ & 0.15 & NA & NA \\
\hline AVF & $0.32(0.24-0.42)$ & $<0.01$ & $0.38(0.28-0.51)$ & $<0.01$ \\
\hline Hypertension & $0.99(0.70-1.40)$ & 0.94 & NA & NA \\
\hline DM & $1.41(1.09-1.82)$ & $<0.01$ & $1.17(0.90-1.53)$ & 0.25 \\
\hline Smoker & $0.99(0.73-1.34)$ & 0.93 & NA & NA \\
\hline CVD & $1.30(0.95-1.78)$ & 0.10 & NA & NA \\
\hline CVA & $1.17(0.79-1.72)$ & 0.44 & NA & NA \\
\hline PAOD & $1.00(0.58-1.00)$ & 0.99 & NA & NA \\
\hline
\end{tabular}

AVF Autologous arteriovenous fistula, BMI Body mass index, $\mathrm{Cl}$ Confidence interval, CVA History of cerebrovascular accident, CVD Cardiovascular disease, DM Diabetes mellitus, HR Hazard ratio, NA Not applicable, PAOD Peripheral arterial occlusive disease, VA Vascular access
(26.5\%) AVF female patients and 331 (63.5\%) AVF male patients.

We performed subgroup analyses of the associations between clinical variables and study outcomes in the elderly group $(n=206)$ (Additional file 1 : Tables S1 and S2). Multivariate analysis of factors associated with VA patency indicated that a higher BMI was independently associated with longer primary patency (HR, 0.93; 95\% CI, 0.88-0.99; $P=0.02$ ). Results also demonstrated that AVF (HR, 0.36; 95\% CI, 0.24-0.54; $P<0.01$ ) was independently associated with longer primary patency. Increased age was associated with shorter secondary patency (HR, 1.13; 95\% CI, 1.07-1.20; $P<0.01)$. A Kaplan-Meier survival analysis of elderly patients stratified by BMI $\left(<23 \mathrm{~kg} / \mathrm{m}^{2}\right.$ vs. $\left.\geq 23 \mathrm{~kg} / \mathrm{m}^{2}\right)$ revealed that higher BMI was significantly correlated with longer primary VA patency $(P<0.01)$ and trended towards longer secondary patency $(P=0.06)$ (Fig. 2). Patients with a BMI of at least $23 \mathrm{~kg} / \mathrm{m}^{2}$ presented with an increased primary patency rate at all time points compared to those with a BMI below $23 \mathrm{~kg} / \mathrm{m}^{2}$.

We also performed subgroup analyses of the associations between clinical variables and outcomes according to the type of VA (AVF or AVG). Among patients with AVF placement $(n=521)$, increased age was the only risk factor associated with shorter primary AVF patency (HR, 1.01; 95\% CI, 1.00-1.02; $P=0.08$ ) (Additional file 1: Table S3). DM with AVF showed a trend towards shorter secondary patency (HR, 1.48; 95\% CI, 0.96-2.28; $P=0.08$ ) (Additional file 1: Table S4). Among patients with AVG placement $(n=130)$, increased age was the 
Table 3 Factors associated with secondary VA patency

\begin{tabular}{|c|c|c|c|c|}
\hline & \multicolumn{2}{|l|}{ Univariate } & \multicolumn{2}{|l|}{ Multivariate } \\
\hline & HR $(95 \% \mathrm{Cl})$ & $P$-value & HR $(95 \% \mathrm{Cl})$ & $P$-value \\
\hline Increased age & $1.01(1.00-1.03)$ & 0.104 & NA & NA \\
\hline Female sex & $0.93(0.63-1.38)$ & 0.723 & NA & NA \\
\hline BMl & $1.00(0.95-1.06)$ & 0.884 & NA & NA \\
\hline AVF & $0.53(0.35-0.82)$ & 0.004 & $0.57(0.37-0.87)$ & 0.010 \\
\hline Hypertension & $0.96(0.58-1.59)$ & 0.877 & NA & NA \\
\hline DM & $1.64(1.12-2.40)$ & 0.011 & $1.56(1.07-2.29)$ & 0.02 \\
\hline Smoker & $1.13(0.74-1.73)$ & 0.581 & NA & NA \\
\hline CVD & $1.29(0.82-2.05)$ & 0.272 & NA & NA \\
\hline CVA & $1.32(0.76-2.27)$ & 0.323 & NA & NA \\
\hline PAOD & $0.81(0.33-1.98)$ & 0.643 & NA & NA \\
\hline
\end{tabular}

AVF Autologous arteriovenous fistula, BMI Body mass index, Cl Confidence interval, CVA History of cerebrovascular accident, CVD Cardiovascular disease, DM Diabetes mellitus, HR Hazard ratio, NA Not applicable, PAOD Peripheral arterial occlusive disease, VA Vascular access

only risk factor significantly associated with shorter primary (HR, 1.02; 95\% CI, $1.00-1.04 ; P=0.04$ ) or secondary $(\mathrm{HR}, 1.04 ; 95 \% \mathrm{CI}, 1.00-1.07 ; P=0.03)$ AVG patency, whereas increased BMI was significantly associated with a longer primary AVG patency (HR, 0.92; 95\% CI, 0.87-0.98; $P=0.01$ ) and showed a similar trend toward longer secondary patency (HR, 0.91; 95\% CI, 0.82-1.01; $P=0.08$ ) (Additional file 1 : Tables S5 and S6).

We performed another subgroup analysis based on age $(65-75$ years vs. $\geq 75$ years $)$ in the elderly group
( $\geq 65$ years, $n=206$ ). We found that AVF placement was more often performed in patients aged 65-75 years $(P<0.01)$. Patients aged 75 years and older had a higher prevalence of atherosclerotic risk factors and comorbidities than the 65-75 group. No significant differences in the proportion of patients taking antiplatelet medications $(P=0.77)$, or with early mortality $(P=0.26)$, or maturation failure $(P=0.19)$ were observed between the two elderly patient subgroups, whereas early VA thrombosis was significantly higher in patients older than 75 years $(P=0.03)$ (Additional file 1: Table S7). The mean durations of primary and secondary VA patency for the patients aged 65-75 years were 52.6 months ( $95 \%$ CI, 45.3-59.9 months) and 79.8 months (95\% CI, 74.4-85.2 months), respectively. For those $\geq 75$ years, mean durations were 36.9 months (95\% CI, 41.6-53.5 months, $P=0.013$ ) and 62.4 months (95\% CI, 53.9-70.9 months, $P<0.01)$, respectively. In the adjusted models of patients aged 75 years and older, type of VA (AVF) was the only positive predictor of longer primary patency (HR, 0.31, 95\% CI, 0.14-0.67; $P<0.01$ ) (Additional file 1: Table S8), whereas increased age was the only risk factor significantly associated with shorter secondary patency (HR, 1.20; 95\% CI, $1.06-$ 1.36; $P=0.01$ ). The type of VA (AVF vs. AVG) was not associated with secondary patency duration (HR, 1.93, 95\% CI, 0.60-6.20; $P=0.27$ ) (Additional file 1: Table S9).

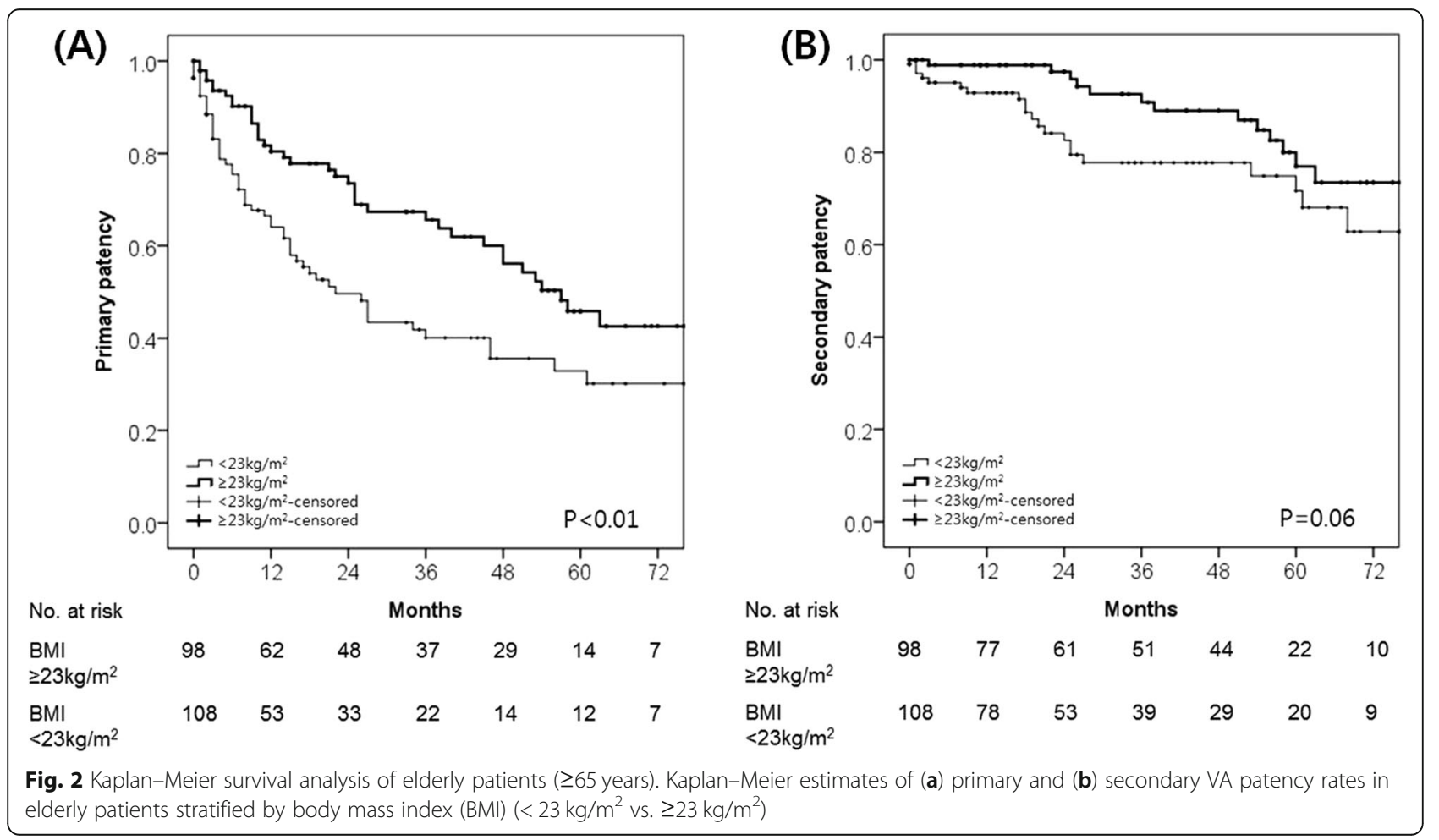




\section{Discussion}

Many patient-level and intervention-specific factors have been suggested as potential predictors of shorter VA patency duration. Although some studies have suggested that VA patency is shorter in women, the elderly, and individuals with DM [27], others have argued that increased age should not be a limiting factor when considering VA options for HD, as similar survival and AVF patency rates were observed for younger and older patients [5-8, 28]. Inconclusive findings across multiple studies highlight the fact that the maintenance of functional VA is a complex and dynamic process, requiring close collaboration among the vascular surgeon, nephrologist and nursing staff to ensure successful VA placement and two-needle cannulation, an adequate HD session, compression for hemostasis, and surveillance. The presence and severity of patient-level factors can also influence the process.

Ethnic differences in environmental and genetic factors, comorbidities, and other characteristics might also influence VA utilization patterns [29]. Although this study cohort consisted of only Korean Asians and is not representative of other ethnic groups, this limitation is also a unique feature of this study, because there is little available data on the association of ethnicity with VA outcomes [30]. The major finding of this study involving an Asian population with CKD requiring HD was that primary VA patency was significantly longer in the nonelderly group, whereas secondary patency was similar between the two groups despite a higher prevalence of atherosclerotic risk factors and comorbidities in the elderly group. Increased age was significantly associated with shorter primary patency but did not significantly affect secondary patency. In the subgroup analyses of the elderly patient group, AVF placement was associated with longer primary VA patency; subgroup analyses according to the type of VA indicated increased age as a significant risk factor for shorter primary AVF patency in this sub-cohort and shorter primary and secondary AVG patency.

Considering advanced age-related complications, patient age is an important factor to consider when determining the ideal type of VA [30]. Reduced life expectancy with increasing age is another competing risk factor for AVF maturation time and use [31]. These issues make it challenging to balance among the factors of the likelihood of patient survival, functional VA survival, and relevant potential complications [30]. The complexities involved in planning VA placement were highlighted in a study of octogenarians who underwent vein mapping preoperatively during the predialysis period and received an AVF [16]; in that cohort, 32\% died before starting HD, and $57.5 \%$ of patients died within 18 months of starting HD. Of the patients who died, 55.5\% died within 6 months of starting HD; $70 \%$ of them had AVFs placed, and there were no matured AVFs available for cannulation prior to the patients' deaths [16]. Although old age alone should not preclude AVF placement because AVFs are likely appropriate for relatively healthy elderly patients with few comorbidities, AVGs may be more suitable for elderly patients with limited life expectancies $[9,16,30,32-34]$. Age and comorbidities were associated with additive and higher risks for shorter functional VA patency. Our analysis indicated that although primary VA patency was significantly longer among nonelderly patients, there were no differences in AVF maturation failure and secondary VA patency between the nonelderly and elderly patients. In our study population, all patients had a nephrologist involved in the planning of VA placement and patient care, and we maintained a strategy of aggressive endovascular and surgical intervention to preserve and restore the patency of failing or failed VAs [17, 34, 35]. We speculate that the planning of VA placement in collaboration with a nephrologist and our aggressive management strategy for dysfunctional VA reduced AVF maturation failure and resulted in the similar secondary VA patency durations observed in the nonelderly and elderly patients. Recent studies and other commentaries may offer additional guidance regarding the planning of VA placement according to factors and conditions associated with old age, including palliative care [30, 36-39].

In the general population, the deleterious effects of obesity on patient survival are well known $[40,41]$; however, several studies have consistently described a survival benefit of a high BMI for chronic HD patients [4246]. In a study of 1486 patients, 340 of whom were obese, only the morbidly obese patients (BMI $\geq 35 \mathrm{~kg}$ / $\mathrm{m}^{2}$ ) had an increased risk of AVF maturation failure [47]; obesity in and of itself was not associated with AVF patency. In our analysis, higher BMI within the normal range was related to longer primary VA patency among elderly patients, and among those with AVGs, higher BMI was significantly associated with longer primary AVG patency and trended toward longer secondary patency. No association between BMI and VA patency was observed in patients with AVFs. Although the recent Westernization of dietary habits has led to increasing BMIs in Asian countries, Asian populations are overall less obese than their Western counterparts. We speculated that the patients who received AVGs had poorer general health status than the patients who received AVFs, and our findings might reflect the generally healthier status of chronic HD patients with higher BMIs compared to the health status of those with lower BMIs.

Our study had some limitations, in particular concerning the retrospective design and small sample size from a single-center cohort. We acknowledge potential 
selection and information biases on the part of the physicians or patients; indication bias and patient selfselection may also have influenced our findings. Decisions about the type of VA were mainly made by the physician based on the expected level of vessel diameter and quality and the estimated risk of AVF maturation failure. We also acknowledge other important factors could have impacted the results that were not available in our data sources, such as uremic signs and symptoms at the time of HD initiation, exact time of CVC exposure, and vessel diameter and quality; these might have accounted for the differences in outcomes we observed compared to other studies. Finally, our study cohort consisted of only Korean Asians, and our findings may not be generalizable to other Asians or other ethnic groups.

\section{Conclusions}

Considering the similar secondary VA patency periods in the nonelderly and elderly groups, and the superior patency of AVFs compared with AVGs, a fistula-first strategy is appropriate for elderly patients who are good candidates for AVF placement based on patient demographics (atherosclerosis risk factors and comorbidities) and vessel diameter and quality as evaluated by physical examination alone or with supplemental ultrasound. In our study population, all patients had a nephrologist involved in planning and patient care from the predialysis stage onward. We expect that collaboration with other specially trained medical staffs and their engagement in the consensus process will further improve VA patency in elderly patients.

\section{Supplementary information}

Supplementary information accompanies this paper at https://doi.org/10. 1186/s12882-019-1604-7.

\footnotetext{
Additional file 1: Table S1. Factors associated with primary VA patency in subgroup analyses of patients aged 65 years and older. This table contains the associations between clinical variables and primary VA patency in the elderly group. Table S2. Factors associated with secondary VA patency in subgroup analyses of patients aged 65 years and older. This table contains the associations between clinical variables and secondary VA patency in the elderly group. Table S3. Factors associated with primary patency in subgroup analyses of patients with AVF placement. This table contains the associations between clinical variables and primary patency in patients with AVF placement. Table S4. Factors associated with secondary patency in subgroup analyses of patients with AVF placement. This table contains the associations between clinical variables and secondary patency in patients with AVF placement. Table S5. Factors associated with primary patency in subgroup analyses of patients with AVG placement. This table contains the associations between clinical variables and primary patency in patients with AVG placement. Table S6. Factors associated with secondary patency in subgroup analyses of patients with AVG placement. This table contains the associations between clinical variables and secondary patency in patients with AVG placement. Table S7. Baseline demographics and clinical characteristics of the $\geq 65$ study population at the time of VA placement. This table contains baseline demographic and
}

clinical characteristics of subgroup analyses based on age (65-75 years vs. $\geq 75$ years) in the elderly group. Table $\mathbf{S 8}$. Factors associated with primary VA patency in subgroup analyses of patients $\geq 75$. This table contains the associations between clinical variables and primary patency in patients $\geq 75$. Table S9. Factors associated with secondary VA patency in subgroup analyses of patients $\geq 75$. This table contains the associations between clinical variables and secondary patency in patients $\geq 75$.

\section{Abbreviations}

AVF: Autologous arteriovenous fistula; AVG: Arteriovenous graft; BMI: Body mass index; CKD: Chronic kidney disease; CVC: Central venous catheter; Cl: Confidence interval; DM: Diabetes mellitus; HR: Hazard ratio; HD: Hemodialysis; PAOD: Peripheral arterial occlusive disease; VA: Vascular access

\section{Acknowledgements}

Not applicable.

\section{Authors' contributions}

SJ, HK, and JWC performed the statistical analysis, interpreted the data, and drafted and critically revised the manuscript. MJK performed statistical analysis. KG, YH, and TWK acquired and interpreted the data. YPC conceived and designed the study, provided supervision, interpreted the data, and critically revised the manuscript. All authors approved the final version of the manuscript and agreed to be accountable for all aspects of the study.

\section{Funding}

None.

\section{Availability of data and materials}

The datasets used and/or analyzed during the current study are available from the corresponding author upon reasonable request.

\section{Ethics approval and consent to participate}

The research was approved by the Institutional Review Board of Asan Medical Center (2018-1318), which waived the need for informed consent.

\section{Consent for publication}

Not applicable.

\section{Competing interests}

The authors declare they have no competing interests.

\section{Author details}

'Division of Vascular Surgery, Department of Surgery, University of Ulsan College of Medicine and Asan Medical Center, 88, Olympic-ro 43-gil, Songpa-gu, Seoul 05505, Republic of Korea. ${ }^{2}$ Division of Nephrology, Department of Internal Medicine, University of Ulsan College of Medicine, Asan Medical Center, Seoul, Republic of Korea. ${ }^{3}$ Department of Clinical Epidemiology and Biostatistics, University of Ulsan College of Medicine, Asan Medical Center, Seoul, Republic of Korea. ${ }^{4}$ Department of Surgery, Mongolian National University of Medical Sciences, Ulaanbaatar, Mongolia.

Received: 15 April 2019 Accepted: 29 October 2019

Published online: 21 November 2019

\section{References}

1. Park HS, Kim WJ, Kim YK, Kim HW, Choi BS, Park CW, et al. Comparison of outcomes with arteriovenous fistula and arteriovenous graft for vascular access in hemodialysis: a prospective cohort study. Am J Nephrol. 2016;43: $120-8$.

2. NKF-K/DOQI. III. NKF-K/DOQI clinical practice guidelines for vascular access: update 2000. Am J Kidney Dis. 2001;37(Suppl 1):S137-S81.

3. Lok CE. Fistula first initiative: advantages and pitfalls. Clin J Am Soc Nephrol. 2007;2:1043-53.

4. Allon M. Current management of vascular access. Clin J Am Soc Nephrol. 2007;2:786-800

5. Morsy M, Betal D, Nelson S, Malete H, Whitmore A, Chemla E. Pre-emptive angioaccess for haemodialysis in the elderly. Nephrol Dial Transplant. 2011; 26:3666-70. 
6. Weyde W, Letachowicz W, Kusztal M, Porazko T, Krajewska M, Klinger M. Outcome of autogenous fistula construction in hemodialyzed patients over 75 years of age. Blood Purif. 2006;24:190-5.

7. Watorek E, Golebiowski T, Kusztal M, Letachowicz K, Letachowicz W, Augustyniak Bartosik $\mathrm{H}$, et al. Creation of arteriovenous fistulae for hemodialysis in octogenarians. Hemodial Int. 2014;18:113-7.

8. Lazarides MK, Georgiadis GS, Antoniou GA, Staramos DN. A meta-analysis of dialysis access outcome in elderly patients. J Vasc Surg. 2007:45:420-6.

9. DeSilva RN, Patibandla BK, Vin Y, Narra A, Chawla V, Brown RS, et al. Fistula first is not always the best strategy for the elderly. J Am Soc Nephrol. 2013; 24:1297-304.

10. Ko GJ, Rhee CM, Obi Y, Chang TI, Soohoo M, Kim TW, et al. Vascular access placement and mortality in elderly incident hemodialysis patients. Nephrol Dial Transplant. 2018. https://doi.org/10.1093/ndt/gfy254 [Epub ahead of print].

11. Miller PE, Tolwani A, Luscy CP, Deierhoi MH, Bailey R, Redden DT, et al. Predictors of adequacy of arteriovenous fistulas in hemodialysis patients. Kidney Int. 1999;56:275-80

12. Chan MR, Sanchez RJ, Young HN, Yevzlin AS. Vascular access outcomes in the elderly hemodialysis population: a USRDS study. Semin Dial. 2007;20: 606-10

13. Praga M, Merello JI, Palomares I, Bayh I, Marcelli D, Aljama P, et al. Type of vascular access and survival among very elderly hemodialysis patients. Nephron Clin Pract. 2013;124:47-53.

14. Richardson Al 2nd, Leake A, Schmieder GC, Biuckians A, Stokes GK, Panneton JM, et al. Should fistulas really be first in the elderly patient? J Vasc Access. 2009;10:199-202

15. Vachharajani TJ, Moist LM, Glickman MH, Vazquez MA, Polkinghorne KR, Lok CE, et al. Elderly patients with CKD - dilemmas in dialysis therapy and vascular access. Nat Rev Nephrol. 2014;10:116-22.

16. Vachharajani TJ, Moossavi S, Jordan JR, Vachharajani V, Freedman BI, Burkart $J M$. Re-evaluating the fistula first initiative in octogenarians on hemodialysis. Clin J Am Soc Nephrol. 2011;6:1663-7.

17. Jeong S, Kwon H, Chang JW, Kim MJ, Ganbold K, Han Y, et al. Patency rates of arteriovenous fistulas created before versus after hemodialysis initiation. PLoS One. 2019;14:e0211296.

18. Han Y, Choo SJ, Kwon H, Lee JW, Chung CH, Kim H, et al. Effects of upperextremity vascular access creation on cardiac events in patients undergoing coronary artery bypass grafting. PLoS One. 2017:12:e0184168.

19. Vascular Access 2006 Work Group. Clinical practice guidelines for vascular access. Am J Kidney Dis. 2006;48(Suppl 1):S176-247.

20. Kim SM, Han Y, Kwon H, Hong HS, Choi JY, Park H, et al. Impact of a preoperative evaluation on the outcomes of an arteriovenous fistula. Ann Surg Treat Res. 2016;90:224-30.

21. Sidawy AN, Spergel LM, Besarab A, Allon M, Jennings WC, Padberg FT Jr, et al. Society for Vascular Surgery. The Society for Vascular Surgery: clinical practice guidelines for the surgical placement and maintenance of arteriovenous hemodialysis access. J Vasc Surg. 2008;48(5 Suppl):2S-25S.

22. Al-Jaishi AA, Oliver MJ, Thomas SM, Lok CE, Zhang JC, Garg AX, et al. Patency rates of the arteriovenous fistula for hemodialysis: a systematic review and meta-analysis. Am J Kidney Dis. 2014;63:464-78.

23. Dember LM, Imrey PB, Beck GJ, Cheung AK, Himmelfarb J, Huber TS, et al. Objectives and design of the hemodialysis fistula maturation study. Am J Kidney Dis. 2014;63:104-12.

24. Bylsma LC, Gage SM, Reichert H, Dahl SLM, Lawson JH. Arteriovenous fistulae for haemodialysis: a systematic review and meta-analysis of efficacy and safety outcomes. Eur J Vasc Endovasc Surg. 2017;54:513-22.

25. Korn A, Alipour H, Zane J, Shahverdiani A, Ryan TJ, Kaji A, et al. Factors associated with early thrombosis after arteriovenous fistula creation. Ann Vasc Surg. 2018;49:281-4.

26. Norgren L, Hiatt WR, Dormandy JA, Nehler MR, Harris KA, Fowkes FG, TASC II Working Group. Inter-society consensus for the management of peripheral arterial disease (TASC II). Eur J Vasc Endovasc Surg. 2007:33(Suppl 1):S1-S75.

27. Almasri J, Alsawas M, Mainou M, Mustafa RA, Wang Z, Woo K, et al. Outcomes of vascular access for hemodialysis: a systematic review and meta-analysis. J Vasc Surg. 2016;64:236-43.

28. Lok CE, Oliver MJ, Su J, Bhola C, Hannigan N, Jassal SV. Arteriovenous fistula outcomes in the era of the elderly dialysis population. Kidney Int. 2005;67: 2462-9.

29. Zarkowsky DS, Arhuidese IJ, Hicks CW, Canner JK, Qazi U, Obeid T, et al. Racial/ethnic disparities associated with initial hemodialysis access. JAMA Surg. 2015;150:529-36
30. Woo K, Lok CE. New insights into Dialysis vascular access: what is the optimal vascular access type and timing of access creation in CKD and Dialysis patients? Clin J Am Soc Nephrol. 2016;11:1487-94.

31. US Renal Data System. Incidence, prevalence, patient characteristics, and treatment modalities. In: USRDS 2015 Annual data report: atlas of chronic kidney disease and end-stage renal disease in the United States, National Institutes of Health. Bethesda: National Institute of Diabetes and Digestive and Kidney Diseases; 2015. p. 222.

32. Cui J, Steele D, Wenger J, Kawai T, Liu F, Elias N, et al. Hemodialysis arteriovenous fistula as first option not necessary in elderly patients. J Vasc Surg. 2016:63:1326-32.

33. Jadlowiec CC, Mannion EM, Lavallee M, Brown MG. Hemodialysis access in the elderly: outcomes among patients older than seventy. Ann Vasc Surg. 2016;31:77-84.

34. Woo K, Goldman DP, Romley JA. Early failure of dialysis access among the elderly in the era of fistula first. Clin J Am Soc Nephrol. 2015;10:1791-8.

35. Kim SM, Ko HK, Noh M, Ko GY, Kim MJ, Kwon TW, et al. Factors affecting patency following successful percutaneous intervention for dysfunctional hemodialysis vascular access. Ann Vasc Surg. 2018;47:54-61.

36. Tamura MK, Tan JC, O'Hare AM. Optimizing renal replacement therapy in older adults: a framework for making individualized decisions. Kidney Int. 2012:82:261-9.

37. O'Hare AM. Vascular access for hemodialysis in older adults: a "patient first" approach. J Am Soc Nephrol. 2013;24:1187-90.

38. Masengu A, Hanko JB, Maxwell AP. Optimizing outcomes in the elderly with end-stage renal disease-live long and prosper. J Vasc Access. 2015;16:439-45.

39. Lomonte C, Forneris G, Gallieni M, Tazza L, Meola M, Lodi M, et al. The vascular access in the elderly: a position statement of the vascular access working Group of the Italian Society of nephrology. J Nephrol. 2016;29:17584.

40. Poirier P, Giles TD, Bray GA, Hong Y, Stern JS, Pi-Sunyer FX, et al. American Heart Association. Obesity Committee of the Council on nutrition, physical activity, and metabolism. Obesity and cardiovascular disease: pathophysiology, evaluation, and effect of weight loss: an update of the 1997 American Heart Association scientific statement on obesity and heart disease from the obesity Committee of the Council on nutrition, physical activity, and metabolism. Circulation. 2006:113:898-918.

41. Prospective Studies Collaboration, Whitlock G, Lewington S, Sherliker P, Clarke R, Emberson J, Halsey J, et al. Body-mass index and cause-specific mortality in 900000 adults: collaborative analyses of 57 prospective studies. Lancet. 2009;373:1083-96.

42. Arhuidese IJ, Obeid T, Hicks C, Qazi U, Botchey I, Zarkowsky DS, et al. Vascular access modifies the protective effect of obesity on survival in hemodialysis patients. Surgery. 2015;158:1628-34.

43. Kalantar-Zadeh K, Streja E, Molnar MZ, Lukowsky LR, Krishnan M, Kovesdy $C P$, et al. Mortality prediction by surrogates of body composition: an examination of the obesity paradox in hemodialysis patients using composite ranking score analysis. Am J Epidemiol. 2012:175:793-803.

44. Lievense $H$, Kalantar-Zadeh K, Lukowsky LR, Molnar MZ, Duong U, Nissenson A, et al. Relationship of body size and initial dialysis modality on subsequent transplantation, mortality and weight gain of ESRD patients. Nephrol Dial Transplant. 2012;27:3631-8

45. Park J, Jin DC, Molnar MZ, Dukkipati R, Kim YL, Jing J, et al. Mortality predictability of body size and muscle mass surrogates in Asian vs white and African American hemodialysis patients. Mayo Clin Proc. 2013;88:479-86.

46. Ricks J, Molnar MZ, Kovesdy CP, Kopple JD, Norris KC, Mehrotra R, et al. Racial and ethnic differences in the association of body mass index and survival in maintenance hemodialysis patients. Am J Kidney Dis. 2011;58: 574-82.

47. Chan MR, Young HN, Becker YT, Yevzlin AS. Obesity as a predictor of vascular access outcomes: analysis of the USRDS DMMS wave II study. Semin Dial. 2008:21:274-9.

\section{Publisher's Note}

Springer Nature remains neutral with regard to jurisdictional claims in published maps and institutional affiliations. 